\title{
Problems and tasks of using digital technologies in agriculture
}

\author{
Viktor V. Alt ${ }^{1,2}$, Maxim S. Chekusov ${ }^{3}$, Elena A. Balushkina ${ }^{1}$ and Svetlana P. Isakova ${ }^{1}$ \\ ${ }^{1}$ Siberian Federal Scientific Centre of Agro-Biotechnologies of the Russian Academy of Sciences, Novosibirsk, Russia \\ ${ }^{2}$ Novosibirsk State Technical University, Novosibirsk, Russia \\ ${ }^{3}$ Omsk Agrarian Scientific Center, Omsk, Russia
}

\begin{abstract}
Digitalization of agricultural production is an existing reality. About $50 \%$ of farms to some extent use elements of digitalization in the implementation of technological and managerial tasks. A system analysis to the objects of agricultural production, as to the information environment when describing them in the information space, is applied to the study. The main problems of digitalization of agriculture associated with large amounts of data and the required accuracy of the resulting solutions are shown. The main tasks in the use of digitalization by agricultural producers are identified and justified. The general requirements for the volume of information for solving problems of agriculture, crop production and means of processing this information are revealed. The amount of information when using digital methods of managing technological processes in agriculture is determined from the necessary resolution when managing technological processes and the volume of arable land in the subject of Russia. The analysis of positive trends allowed us to formulate main messages in the application of digital technologies in agricultural production at the present stage of its development.
\end{abstract}

\section{Keywords}

Agricultural factors, digital information, resolution, volume of information, labor productivity.

\section{Introduction}

"Strategy without tactics is the slowest path to victory. Tactics without strategy are just a fuss before defeat". Sun Tzu, Chinese strategist and thinker who lived in the VI century BC, author of the famous treatise on military strategy.

Digital technologies in the management of agricultural production are a set of software methods for processing natural production information using technical means and computers [1, 2]. There is no consensus on what should be considered a priority, and what can't be solved taking into account the realities in specific conditions. It is also not decided what difficulties await those who want to benefit from the use of digital technologies and what opportunities open up when using these technologies. It offers databases and knowledge, platform solutions, big data systems, artificial intelligence systems, etc. The use of digital technologies today requires the formulation of approaches to their application. They should be based on the

SDM-2021: All-russian conference, August 24-27, 2021, Novosibirsk, Russia

$\bigoplus$ altviktor@ngs.ru (V.V. Alt); chekusov@anc55.ru (M.S. Chekusov)

(c) (1) $\odot 2021$ Copyright for this paper by its authors. Use permitted under Creative Commons License Attribution 4.0 International (CC BY 4.0).

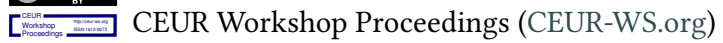


analysis of the types of information, its volumes and the change in the paradigm of information support for agricultural production.

\section{Discussion}

To formulate the main messages in the application of digital technologies in agricultural production, it is planned to solve the following tasks using a system analysis of hidden relationships and implicit functional dependencies:

- determination of structural relations of agricultural production objects;

- estimation of the amount of information that characterizes the multidimensional space in the aggregate of all objects as a whole and each separately;

- formation of the paradigm of information support and management of technological processes of agricultural production using expert systems and artificial intelligence systems.

The analysis of trends in the digitalization of agricultural production showed an increase in production efficiency while maintaining soil fertility, a decrease in social tension in rural areas, and an increase in the influx of young people to rural areas $[3,4,5]$. In the course of our research, we applied a systematic analysis of the commonality of relationships. These connections make up agricultural production as a system consisting of independent subsystems. They have stable connections in the higher-level system and have the property of changing independently as subsystems, and changing as a whole within the system. The method of limiting transition of states of subsystems is applied to establish mutual influence on the system as a whole and its subsystems. This approach to the systematic representation of agricultural (grain) production is legitimate. The proof of this was the creation of a number of information models in our research team over the years using the above-mentioned concept (machinetractor unit, agricultural machine, transmission, engine, plant, phytophages, agrophytocenosis, etc.). The use of information models provided the creation of more than 20 databases and knowledge $[3,4,5,6,7]$. Subject-oriented search algorithms of a tree-like search system are applied.

What is the reliable knowledge of the digitalization of agriculture? Agriculture is characterized by features that dictate the use of modern capabilities for processing and analyzing digital information:

- multi-dimensionality of factors that characterize production and technological processes;

- agroclimatic distribution of farms (more than 100 million hectares);

- diversity of societies;

- the multiplicity of species, breeds, varieties of animals and plants.

The inevitability of incomplete information when making management decisions exists in agricultural production. This is due to the multifunctional nature of management facilities in agriculture. These include: the environment, land, plants, animals, machines and society (rural people with their environment: agro-climatic conditions, social conditions, financial and monetary structure of income and expenses, transport infrastructure, production logistics, etc.) 
These features determine usage need of innovative digital technologies: artificial intelligence, robotics, Internet of things, unmanned aerial vehicles, as well as the introduction of a number of new hardware, software, mobile applications, sensor technologies and big data processing systems $[8,9,10]$.

The areas and directions in agriculture affected by digitalization are presented below:

- detection of diseases, pests and weeds by processing images obtained by drones using artificial intelligence;

- forecast weather conditions by receiving, processing and analyzing data from local weather stations and statistical data for previous periods;

- precision farming using GPS navigation, drones, digital mapping and soil assessment;

- application of fertilizers and protective equipment using the analysis of data obtained by aerial photography, crop monitoring and spot application of funds using GPS navigation;

- monitoring plant growth using drone flyovers, calculating vegetation indices, tracking product quality and forecasting yields;

- control of the production process using information systems that provide tools for economic and other calculations, field history and document management;

- monitoring of agricultural machinery using systems for tracking its movement, fuel consumption and remote monitoring of the state of equipment;

- purchase and sale of equipment using Internet portals, mobile applications, etc.

Agricultural production is characterized by a combination of processes with a periodicity of several microseconds (in the task of ensuring the operability of tractors, combines and other equipment) to three years (in the task of updating the herd of animals). These examples demonstrate the polar requirements for speed, volume of information, and size of information messages. It is necessary to formulate approaches to the formation of tools and software at the current stage of development of both agricultural production and digital technologies.

Each of the subjects of agricultural production management is associated with the multifunctional nature of the interrelationships of management objects in the decision-making process. We can systematize them in a generalized form as the environment, the earth, plants, animals, machines, and society. Society is a rural person with his social and living conditions, financial and monetary system of income and expenses, transport infrastructure, production logistics, etc. All this can be represented as 8 and sometimes 12 types of resources. They interact in a common set and are represented by an $\mathrm{n}$-dimensional space, the size of which is determined by the number of resources under consideration [11]. A person lives in a 4-dimensional space (width, length, height, and time). When the dimensionality of the space increases (the first derivative of any of the metrics of the four-dimensional space can be represented as the fifth coordinate), one feels a certain discomfort. The analysis of the flow of processes in 8, 12-dimensional space for him is a task of insurmountable complexity.

To solve this problem, a person assumes the immateriality or limitlessness of some resources in order to reduce the dimensionality of space. Thus, he makes private decisions. As a result, incomplete knowledge of the processes in agricultural production is formed [12].

As Friedrich von Hayek (an economist and philosopher of the twentieth century) argued, every person has only a particle of knowledge, so in the process of managerial and entrepreneurial 
Table 1

Grain production volumes in the Novosibirsk region

\begin{tabular}{cccc}
\hline Indicator, average value & $1988-1992$ & $2016-2019$ & +Growth, \% \\
\hline Crop area, thousands of ha & 1999 & 1492.9 & -25.6 \\
Gross collection, thousands of tons & 2668 & 2522.7 & -0.05 \\
Yield, tons/ha & 1.33 & 1.69 & 27 \\
\hline
\end{tabular}

activity, mistakes of actions or decisions are objectively inevitable. This is the first and one of the main messages of the use of digital technologies in agricultural production.

The desire to increase the productivity of fields and farms is always associated with the need for a deeper knowledge and understanding of the processes that determine the functioning of all components in agriculture and animal husbandry. Fields, varieties, breeds, conditions for their growth and development, processing into products of human life support and the environment of its existence and habitat are associated with a quantitative and qualitative description of the entire diversity of the universe. The more deeply we know the world, the more parameters, characteristics, and descriptions we use to create articles, books, databases, and knowledge [7].

The need to use large databases and their analysis for making management decisions dictates the timeliness of changing the paradigm of information support for digitalized agricultural production $[12,13]$. We proposed a paradigm of information support for digitalized agricultural production.

The efficiency of grain production is largely determined by the choice of varieties and technologies in all their diversity in accordance with the agro-climatic (soil diversity, temperature, moisture) and agro-landscape features of the farm location. This information can only be obtained by remote sensing of fields with a resolution of up to $0.01-0.003 \mathrm{~m}$. Such accuracy entails the need to process large amounts of data.

We consider the Novosibirsk region and its acreage - 1900 thousand hectares as an example to determine the possible necessary amounts of information. This territory is characterized the entire spectrum of types and varieties of agricultural crops, growing and harvesting technologies. Solving the problems of digital management of them involves the use of a digital platform with processed volumes of about 2 petaflops. Invariant solutions to this problem are possible only on the basis of digital information technologies using big-date, digital platforms, databases, knowledge bases, expert systems and artificial intelligence systems. This is next of the main messages of the use of digital technologies in agro-industrial production.

The agro-climatic potential of Siberia is 4-6 times lower than the same indicator in Europe and the United States. In Western Siberia it is $58-63 \%$ of the potential of Russia, and in Transbaikalia is $38-43 \%$ (according to Academician of the Russian Academy of Sciences Goncharov P.L.). In Siberia with the expansion of the use of high-intensity, low-energy and resource-saving technologies the production of competitive products is ensured (Table 1) [4, 7].

Arable land in the Novosibirsk region has decreased by $25 \%$ in 30 years. At the same time the gross grain harvest has decreased by $0.05 \%$, and the yield has increased by $27 \%$. The results of the competitive test showed a yield of 4.5 to 7.6 tone on ha of zoned wheat varieties according to Academician of the Russian Academy of Sciences A.N. Vlasenko, which indicates their 
advantage over non-zoned varieties. Varieties of Siberian selection occupy 95-99\% of the grain wedge in the region.

The share of the rural population of Russia decreased by 2 times over the period 1959-2018, according to Rosstat, and by 2019 reached $25.3 \%$ of the total population [13]. In 2001-2010 the number of employees in agricultural organizations decreased by about 5 times [14]. The negative trend in terms of providing the village with specialists continues. For the sake of objectivity, it should be noted that large commodity producers and agricultural holdings don't experience an acute shortage in personnel due to high productivity, intensification and remuneration. The analysis of positive and negative trends in rural areas in the field of changes in the human resource allows us to conclude that there is a chronic shortage of highly qualified specialists among workers, people with higher and secondary specialized education who seek to use digital technologies in production.

If we consider the six types of resources ("land", "plants", "environment", "machines", "animals" and "society") in unity and in the system of grain production, it becomes obvious that we in Siberia objectively have the possibility of doubling grain production [15].

Most authors believe that the factors that ensure the growth of grain production are:

- varieties of intensive grain cereals;

- plant nutrition (its replenishment is provided by organic and mineral fertilizers);

- protection of plants from diseases, pests and weeds;

- increase the productivity of agricultural machines (by increasing their working width, power, automation, etc.).

This is certainly true. However, the task of leveling the causes that hinder the growth of grain production is to formalize the limiting factors and find ways to overcome them.

For example, take the Trans-Baikal Territory. There are years when there is no moisture in the meter layer of the soil, and even poplars dry up. But in August, September, rains come, leading to flooding. Can this moisture be used? Yes, you can, and this technological technique is known. This is a deep loosening. It ensures the accumulation of moisture in the meter layer of the soil and its use in the next growing season. The use of deep loosening allowed us to obtain 3.5 ton on ha of spring wheat Novosibirsk 29 in the SP Sterlikov V.V. Karymsky district of the Trans-Baikal Territory.

The search for techniques and technologies that eliminate limiting factors is multidimensional. Their composition and ways to overcome them can be determined only by analyzing digital simulation models of agrobiocenosis for a specific territory. This is the next message in the development and development of digital information technologies in agricultural production.

We have already discussed the unifying role of "society" for all five resources. But not everything is so simple with a more detailed analysis of this role. It should be taken into account that a person as a subject of business processes always tries to maintain their advantages over other business participants, otherwise they will be like everyone else. In such a situation, the principle works: "Do I need this?". Overcoming this situation is possible through science, education and management. Of course, this requires time and financial resources. Yes, it is possible that not all fundamental research is involved in this process, but applied research is definitely a priority. This is the use of the development of information and digital technologies in a particular agricultural enterprise. 
The number of combinations in solving the problems of organizing and implementing agricultural production in a particular farm with 3 technologies of tillage (dump-classic, non-dump, no-tile), 3 levels of intensification (extensive, normal, intensive) and 6 messages of information digital technologies is equal to 247520 options.

\section{Conclusion}

The principles are based on the formulated messages of digital information technologies, which allow them to be used in more than 247520 different combinations and to be applied to the entire variety of farms, depending on their capabilities and desires. The solution to the problems of the transition of agriculture to a highly productive type of production lies in the way of step-by-step resolution of the choice of technologies and ranking this set by the importance for each particular farm of a particular message to eliminate (reduce) the negative impact on the life of the producer of agricultural products.

\section{References}

[1] Dos Santos U.J.L., Pessin G., da Costa C.A., da Rosa Righi R. AgriPrediction: A proactive internet of things model to anticipate problems and improve production in agricultural crops // Computers and Electronics in Agriculture. 2019. Vol. 161. P. 202-213.

[2] Jones J.W., Antle J.M., Basso B. et al. Toward a new generation of agricultural system data, models, and knowledge products: State of agricultural systems science // Agricultural Systems. 2017. Vol. 155. P. 269-288.

[3] Fedorenko V.F., Mishurov N.P., Buklagin D.S., Goltyapin V.Ya., Golubev I.G. Digital agriculture: state and prospects of development: Scientific Ed. Moscow: FSBI "Rosinformagrotech", 2019. $316 \mathrm{p}$.

[4] Fedorenko V.F., Chernoivanov V.I., Goltyapin V.Ya., Fedorenko I.V. World trends in the intellectualization of agriculture: Nauch. analyte. review. Moscow: FSBI "Rosinformagrotech", 2018. $232 \mathrm{p}$.

[5] Gostev A.V., Pykhtin A.I. The structure of the normative reference database of the support system for agricultural producers on the rational choice of highly profitable adaptive technologies for the cultivation of grain crops // Modern High-tech Technologies. 2018. Vol. 2. P. 37-41.

[6] Tkachenko V.V. Methodology of multi-criteria complex assessment and selection of technology for cultivating agricultural crops // Scientific Journal of KubGAU. 2016. Vol. 123. No. 09. P. 1-19.

[7] Results of the study of the intra-field heterogeneity of the soil cover: Report of scientific research work No. 05-2017. Novokubansk branch of FGBNU "Rosinformagrotech" (KubNIITiM), 2017. $116 \mathrm{p}$.

[8] Phillips P.W.B., Relf-Eckstein J.-A., Jobe G., Wixted B. Configuring the new digital landscape in western Canadian agriculture // Wageningen Journal of Life Sciences. 2019. Vol. 90. Art. no. 100295.

[9] Talaviya, Shah D., Patel N., Yagnik H., Shah M. Implementation of artificial intelligence in 
agriculture for optimisation of irrigation and application of pesticides and herbicides // Artificial Intelligence in Agriculture. 2020. Vol. 4. P. 58-73.

[10] Jha K., Doshi A., Patel P., Shah M. A comprehensive review on automation in agriculture using artificial intelligence // Artificial Intelligence in Agriculture. 2019. Vol. 2. P. 1-12.

[11] Alt V., Isakova S., Balushkina E. Digitalization: Problems of its development in modern agricultural production // 8th Innovative Technologies in Science and Education, ITSE 2020. 2020. Vol. 210. Art. no. 10001.

[12] Paptsov A.G., Altukhov A.I., Kashevarov N.I., Pershukevich P.M., Denisov A.S., Rudoy E.V. et al. Forecast of scientific and technological development of the crop production industry, including seed production and organic farming in Russia, in the period up to 2030 // Novosibirsk State Agrarian University, Sib. Feder. Center for Agrobiotechnologies of the RAS, Institute of Cytology and Genetics SB RAS, VNC VNIIEKH. Novosibirsk: Publ. House of NGAU "Zolotoy kolos", 2019. 100 p.

[13] Regions of Russia. Socio-economic indicators. 2020: Stat. Sat. / Rosstat. Moscow, 2020. $1242 \mathrm{p}$.

[14] Alt V.V., Bobrova T.N., Kolpakova L.A., et al. Methodological provisions on the information support of machine agricultural technologies for the production of spring wheat grain at the level of an agricultural enterprise. Novosibirsk, 2017. 56 p.

[15] Donchenko A.S., Kalichkin V.K., Mityakova R.P. et al. Interregional scheme of placement and specialization of agricultural production in the subjects of the Russian Federation of the Siberian Federal District: Recommendations. Novosibirsk: SB RAS, 2016. 255 p. 